\title{
The active form of MMP-3 is a marker of synovial inflammation and cartilage turnover in inflammatory joint diseases
}

\author{
Shu Sun ${ }^{1 *}$, Anne-Christine Bay-Jensen ${ }^{1}$, Morten A Karsdal ${ }^{1}$, Anne Sofie Siebuhr ${ }^{1}$, Qinlong Zheng ${ }^{2}$,
} Walter P Maksymowych ${ }^{3,4}$, Thorbjørn G Christiansen ${ }^{5}$ and Kim Henriksen ${ }^{1}$

\begin{abstract}
Background: Matrix metalloproteinase-3 (MMP-3) plays an important role in the pathology of rheumatoid arthritis (RA) and ankylosing spondylitis (AS). Measurement of active MMP-3 in clinical samples could provide information about progression of rheumatoid diseases, and potentially response to treatment. Hence, we aimed to develop a sensitive assay specifically measuring the active form of MMP-3 (act-MMP-3) both in ex vivo models and in human sera.

Methods: A monoclonal antibody against the first 6 amino acids of act-MMP-3 was developed, and the specificity was carefully tested by comparing total and active MMP-3. A technically robust act-MMP-3 ELISA was produced. For biological validation, human synovial membrane and human cartilage explant (HEX) culture models were measured and compared by ELISA and immunoblots. For clinical relevance, the serum levels of act-MMP-3 in AS and RA patients before and after anti-TNF-a treatment were evaluated.
\end{abstract}

Results: A highly specific and technically robust ELISA detecting act-MMP-3 in serum was developed. The lower limit of detection was $33.7 \mathrm{pg} / \mathrm{mL}$. The dilution and spiking recovery of human serum was within $100 \pm 20 \%$. The average intra- and inter-assay variations were $3.1 \%$ and $13.5 \%$ respectively.

High levels of act-MMP-3 expression were observed in human synovial membrane culture and oncostatin M and TNF-a stimulated human cartilage. In a cross-sectional study of both AS and RA patients, serum act-MMP-3 level was correlated with C-reactive protein (CRP) and erythrocyte sedimentation rate (ESR). In addition, in patients receiving anti-TNF-a treatment, the serum level of act-MMP-3 was significantly reduced compared to baseline level reflecting the anti-inflammatory effects of the treatment.

Conclusion: We have successfully developed an assay measuring act-MMP-3 in human serum showing correlation to inflammatory markers. Further studies are required to clarify, whether act-MMP-3 can serve as a predictive marker for outcome in chronic rheumatoid disorders.

Keywords: MMP-3, Active form, Ankylosing spondylitis, Rheumatoid arthritis, Serum

\section{Background}

Ankylosing spondylitis (AS) is a chronic inflammatory rheumatic disease, which primarily affects the spine and sacroiliac joints [1]. Rheumatoid arthritis (RA) is another chronic autoimmune disease with progressive synovial joint destruction. Increased turnover of extracellular matrix (ECM) proteins has been found in both AS and RA, and

\footnotetext{
* Correspondence: ssu@nordicbioscience.com

${ }^{1}$ Nordic Bioscience Biomarkers and Research, Herlev, Denmark

Full list of author information is available at the end of the article
}

the MMPs are known to be important proteases responsible for ECM protein degradation [2]. Previous studies have indicated MMP-3 as a pathological mediator in AS, as well as RA $[3,4]$.

The pathology of RA includes different cells of the joint such as chondrocytes, $T$ cells, fibroblast-like synoviocytes and macrophages, features which also are seen in AS. Among them, fibroblast-like synoviocytes are thought to be key players in RA $[5,6]$, and they are known to express MMP-3, which is linked to their ability to cleave aggrecan, collagen type II, IX, X, link proteins and others 
in the joint $[7,8]$. In addition, MMP-3 can activate other MMPs, such as pro-MMP-1, pro-MMP-8, pro-MMP-9 and pro-MMP-13 [9-12], and hence MMP-3 is considered an important pathological mediator of AS and RA.

MMP-3 is composed of a signal peptide, which is cleaved off during the secretion process, a pro-domain, which is cleaved during the activation process, a catalytic domain which has a conserved zinc-binding site, a hinge domain, and a hemopexin domain [13]. Pro-MMP-3 is secreted to the ECM in its latent form and is then activated by removal of the pro-peptide, which is mediated by serine proteases, plasmin and trypsin $[14,15]$.

Serum levels of MMP-3 have been reported elevated in RA patients compared with osteoarthritis patients [16], and to be associated with the development of structural damage in RA patients [17]. Furthermore, serum MMP-3 levels at baseline were shown to be predictive of radiographic progression in an RA cohort [18]. In AS, MMP-3 was also found to be a predictor of structural progression [19]. Collectively, the line of data underscores the pathological relevance of MMP-3 in arthritic diseases. In addition, elevated MMP-3 expression has been observed in isolated synovium and cartilage [20,21].

Presently, two methods are used to measure serum levels of MMP-3, and these measure either total MMP-3 protein [22] or the activity of MMP-3 using a substrate; however, neither of these approaches provides specific information about the active form of MMP-3. It is known that the cleavage capacity of MMP- 3 is regulated by three levels: synthesis, activation and inhibition. Only act-MMP3 has the ability to cleave ECM proteins, while the concentration of latent form only reflects the potential of MMP-3 to degrade proteins. So act-MMP3 may provide other information beyond total MMP-3, like the activation of proMMP3, and the abnormal imbalanced binding between act-MMP3 and inhibitors in rheumatoid diseases. Moreover, it is also useful in drug screening process which can show the treatment efficiency on reducing active protease. Since pro-MMP3 concentration is much higher than actMMP3 in biological fluid, this information may have been masked by total MMP3 measurement. So in this study we focused on developing an ELISA specifically detecting active MMP-3, and we characterized it using both ex vivo cultures of human cartilage and synovium, and serum samples from AS and RA cohorts.

\section{Methods}

\section{Reagents}

All the reagents used in this study were standard high quality chemicals from Sigma (St.Louis, MO, USA) and Merck (Whitehouse Station, NJ, USA) unless specifically mentioned. All the peptides for monoclonal antibody development were a) immunogenic peptide: FRTFPG IPKW-GGC b) screening peptide: FRTFPGIPKW-biotin c) standard peptide: FRTFPGIPKW d) elongated peptide: HFRTFPGIPKW. All the peptides were purchased from the Chinese Peptide Company, China.

\section{Development of monoclonal antibody}

All the mice were specific pathogen free (SPF) animals and housed in SPF animal facility with $12 \mathrm{~h}$ light/dark cycle. The mice had free access to food and water. All the work on mice was approved by Beijing laboratory animal administration office and animal ethics committee of Nordic Bioscience (Beijing).

We used the first 10 amino acids of the $\mathrm{N}$-terminal $\left({ }^{100}\right.$,FRTFPGIPKW $\left.{ }^{109}\right)$ as the immunogenic peptide to generate specific neo-epitope monoclonal antibodies. The methods used for monoclonal antibody development were as previously described [23]. Briefly, six Balb/c mice (female, 4 to 6 weeks old) were immunized subcutaneously with $200 \mu \mathrm{l}$ emulsified antigen and $60 \mu \mathrm{g}$ of KLH conjugated immunogenic peptide. Consecutive immunizations were performed at two-week intervals in Freund's incomplete adjuvant, until stable sera titer levels were reached, and the mice were bled from the 3rd immunization on. At each bleeding, the serum titer was detected and the mouse with highest antiserum titer and the best native reactivity was selected for fusion. The selected mouse was rested for 1 month followed by intravenous boosting with $50 \mu \mathrm{g}$ of KLH conjugated immunogenic peptide in $100 \mu \mathrm{l} 0.9 \%$ sodium chloride solution 3 days before isolation of the spleen for cell fusion.

The fusion procedure has been described [24]. Briefly, the spleen cells from the immunized mouse with best antiserum titer and native reactivity were fused with SP2/ 0 myeloma fusion partner cells. The fusion cells were raised in 96-well plates and incubated in a 5\% CO2 incubator. Here standard limited dilution was used to promote monoclonal growth. After seven to ten days of culture, supernatants were screened in a competitive ELISA setting. Cell lines specific to standard peptide and without crossreactivity to elongated peptide were selected and subcloned. At last the antibodies were purified.

\section{In vitro Activation of MMP-3}

$10 \mu \mathrm{g}$ of Pro-MMP-3 (cat.no PF063, Calbiochem) was dissolved in $100 \mu \mathrm{L}$ MMP buffer (100 mM Tris-HCl, $100 \mathrm{mM}$ $\mathrm{NaCl}, 10 \mathrm{mM} \mathrm{CaCl}_{2}, 2 \mathrm{mM} \mathrm{Zn}$ acetate, $\mathrm{pH}$ 8.0). $1 \mu \mathrm{g}$ proMMP-3 was mixed with $1.1 \mu \mathrm{L} 10 \mathrm{mM}$ APMA and incubated at $37^{\circ} \mathrm{C}$ for 3 hours.

\section{Ex vivo Synovial membrane tissue culture}

Synovial membrane was obtained from total knee replacements of osteoarthritis patients at Gentofte Hospital, Gentofte, Denmark. The study was approved by the Ethics Committee of the Capital Region of Denmark, DK3400 (approval no. HD-2007-0084). Patients were informed 
about the purpose of the study and provided written consent.

Synovial membrane was isolated during surgery and kept in DMEM $+10 \% \mathrm{FCS}$ at $4^{\circ} \mathrm{C}$ until the next day, where experiments were initiated. Synovial membrane was washed 5 times in PBS to limit contamination and to remove excess blood. The synovial membrane was divided into equal pieces (explants) of about $30 \mathrm{mg}$ and placed in a 96 well plate. Explants for the metabolic inactive (MI) group were inactivated by three freeze-thaw cycles. They were placed in a $37^{\circ} \mathrm{C}$ water bath for $5 \mathrm{~min}$, then immediately transferred to liquid nitrogen and stayed for another $5 \mathrm{~min}$, and repeated for 3 times. The explants was cultured in DMEM:F12 for 14 days, where medium was changed every second or third day. Conditioned medium was kept at $-20^{\circ} \mathrm{C}$ until analysis.

\section{Human cartilage explants (HEX) culture}

The human cartilage explants (HEX) culture was performed as described previously [25]. Briefly, human cartilage was collected from cartilage replacement surgery. The study was approved by the Ethics Committee of the Capital Region of Denmark, DK-3400 (approval no. HD-2007-0084). The cartilage explants (16 $\pm 4 \mathrm{mg})$ were placed in 96-well plates and cultured at $37^{\circ} \mathrm{C}, 5 \% \mathrm{CO} 2$ incubator. Each explant was cultured in $200 \mu \mathrm{L}$ of DMEM for 21 days and divided into two groups: 1) without catabolic factors $(\mathrm{W} / \mathrm{O}), 2)$ with the catabolic cytokines oncostatin $\mathrm{M}(10 \mathrm{ng} / \mathrm{mL})$ and TNF- $\alpha(20 \mathrm{ng} / \mathrm{mL})(\mathrm{O}+\mathrm{T})$ to stimulate MMP activity. The culture medium was changed every 2-3 days and the supernatant was collected and stored in $-20^{\circ} \mathrm{C}$ for further use.

\section{Western blotting}

Synovial membrane culture supernatant, HEX supernatant and act-MMP-3 were separated by SDS-PAGE, and proteins were transferred onto nitrocellulose membranes. The membranes were blocked with $5 \%$ skim milk powder in TBS-T buffer, and incubated in room temperature for 2 hours. The membranes were incubated with primary antibody at $4^{\circ} \mathrm{C}$ overnight, followed by three times wash in TBS-T buffer. Then the membranes were incubated in the secondary peroxidase conjugated antibody, and followed by three times wash. Finally, the results were visualized with ECL detection system (cat\# RPN2109, Amersham Pharmacia). The antibody recognizes both pro and active form of MMP-3 was from Abcam (ab38916).

\section{Active MMP-3 assay protocol}

ELISA-plates used for the assay development were Strep tavidin-coated from Roche cat:: 11940279. All ELISA plates were analyzed with ELISA reader from Molecular Devices, SpectraMax M, (CA, USA). The selected monoclonal antibody 7B2 was labeled with horseradish peroxidase (HRP) using the Lightning link HRP labeling kit according to the instructions of the manufacturer (Innovabioscience, Babraham, Cambridge, UK). A 96-well streptavidin plate was coated with screening peptide FRTFPGIPKW-biotin dissolved in coating buffer $(50 \mathrm{mM}$ Tris, $137 \mathrm{mM} \mathrm{NaCl}$, 1\% BSA, $0.05 \%$ Tween-20, 0.36\% Bronidox L5, pH 8.0) and incubated 30 minutes at $20^{\circ} \mathrm{C} .30 \mu \mathrm{L}$ of standard peptide or sample dissolved in incubation buffer $(50 \mathrm{mM}$ Tris, $137 \mathrm{mM} \mathrm{NaCl}, 1 \% \mathrm{BSA}, 0.05 \%$ Tween-20, 0.36\% Bronidox L5, 5\% liquid II, pH 8.0) were added to appropriate wells, and followed by $100 \mu \mathrm{L}$ of conjugated antibody 7B2-HRP. Synovial membrane culture and HEX culture supernatant, serum samples measured in the ELISA were pre-diluted $1: 2$; act-MMP-3 and pro-MMP-3 inhibition test was performed in a serial dilution with the concentration from $1 \mathrm{ng} / \mathrm{ul}$. Then the assay was allowed to incubate at $4^{\circ} \mathrm{C}$ for $20 \pm 1$ hours. Finally, $100 \mu \mathrm{L}$ tetramethylbenzinidine (TMB sens) (Kem-En-Tec cat.4850E) was added and the plate was incubated 15 minutes at $20^{\circ} \mathrm{C}$ in the dark. All the above incubation steps included shaking at $300 \mathrm{rpm}$. After each incubation step the plate was washed five times in washing buffer $(20 \mathrm{mM}$ Tris, $50 \mathrm{mM} \mathrm{NaCl}$, $\mathrm{pH}$ 7.2). The TMB reaction was stopped by adding $100 \mu \mathrm{L}$ of stopping solution $\left(0.1 \% \mathrm{H}_{2} \mathrm{SO}_{4}\right)$ and measured at $450 \mathrm{~nm}$ with $650 \mathrm{~nm}$ as the reference. A standard curve was performed by serial dilution of the standard peptide with the concentration of $0,4.88,9.77,19.53,39.06,78.13,156.25$, $312.5,625,1250,2500$ and $5000 \mathrm{pg} / \mathrm{mL}$. Calibration curve was plotted using a 4-parametric mathematical fit model.

\section{Technical evaluation}

The intra- and inter-assay variation was determined by 10 independent runs of 8 quality control (QC) samples consisting of serum, and each run consisting of double determinations of the samples. The lower limit of detection (LLOD) was determined from 21 zero samples (incubation buffer) and calculated as the mean 3x standard deviation. Dilution recovery was calculated as a percentage of recovery of diluted QC samples from the 100\% sample. Spike recovery was calculated by comparing different concentrations of human cartilage explants supernatant in incubation buffer and in human serum. Finally, for each assay, a master calibrator prepared from synthetic peptides accurately quantified by amino acid analysis was used for calibration purposes.

\section{Clinical samples}

Serum samples from 201 AS patients and 47 control RA patients were analyzed [26]. Of all the patients, 142 AS patients and 47 RA patients received 3 months antiTNF- $\alpha$ treatment after recruitment. At baseline, the Bath AS Disease Activity Index (BASDAI) and the modified Stoke AS Spine Score (mSASSS) were recorded for all the AS patients, while DAS and HAQ were recorded for 


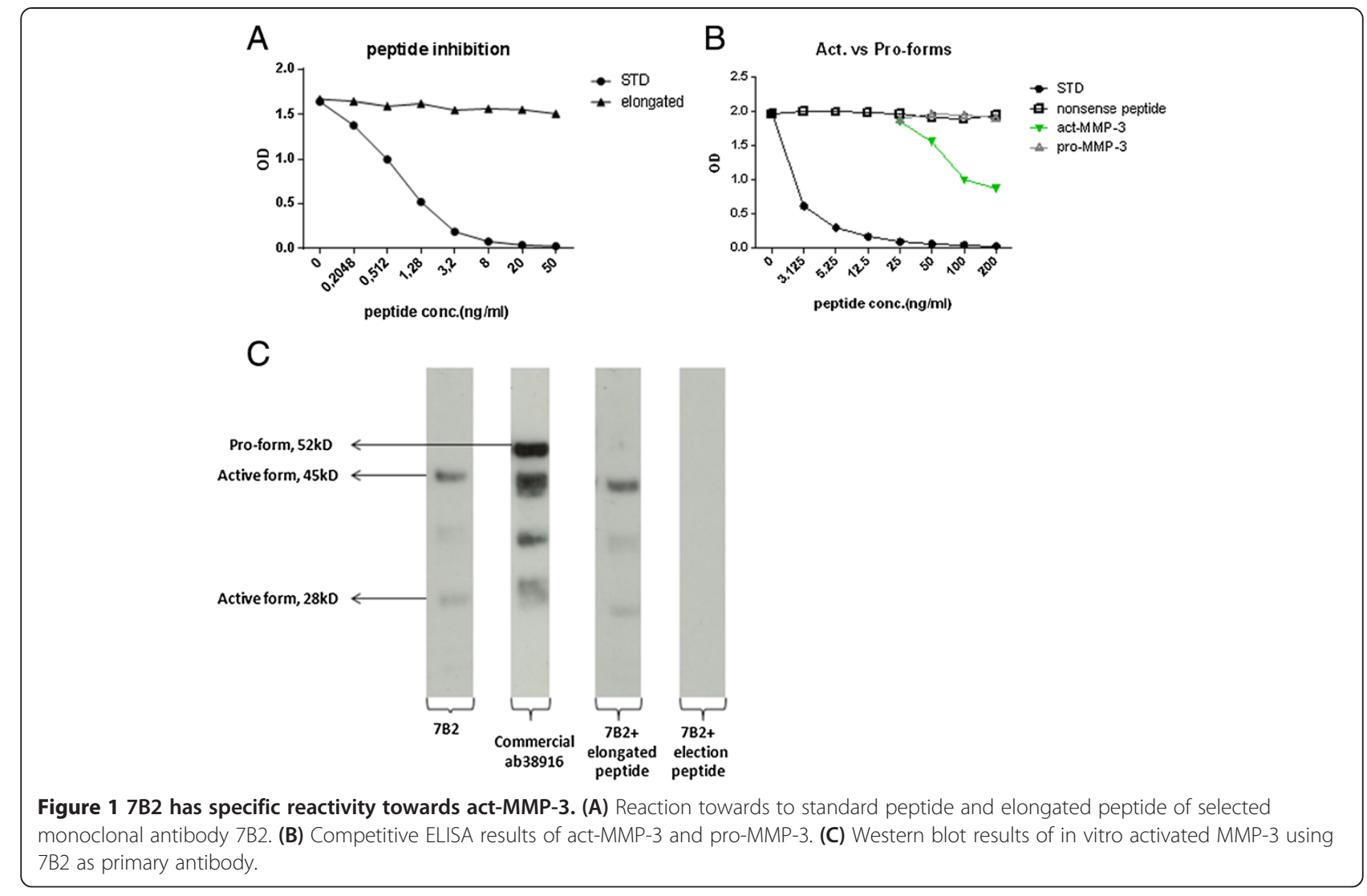

RA patients. CRP (C-reactive protein) concentration and ESR (erythrocyte sedimentation rate) were also recorded for both AS and RA patients. For those patients who have received anti-TNF- $\alpha$ drug, the characteristics mentioned above, except for mSASSS, were also recorded after treatment. In 118 AS patients, mSASSS were recorded after 2 years of followup. All the clinical characteristics used have previously been published by Bay-Jensen $\mathrm{AC}$ et al [26]. Serum samples were thawed from $-80^{\circ} \mathrm{C}$ storage and act-MMP-3 concentrations were measured both at baseline and after treatment. The study was approved by local ethics committee and all patients provided the written informed consent.

\section{Statistics}

Mean values and standard error of the mean (SEM) were calculated using GraphPad Prism, version 6 (GraphPad Software, San Diego, CA, USA). Act-MMP-3 differences between female and male were analyzed using nonparametric Mann-Whitney test. Correlations between actMMP-3 and patient clinical characteristics (age, disease duration, CRP, ESR, BASDAI, mSASSS) were determined by Spearman's test. Significant differences of clinical samples between pre-treatment and post-treatment were determined using the Wilcoxon matched-pairs signed rank test. Significant differences were considered if $\mathrm{P}<0.05$.

\section{Results}

Assessment of antibody performance using the pro and active form MMP-3

When measured in the competitive act-MMP-3 assay applying the 7B2 antibody, the antibody specifically recognized the N-terminal peptide ${ }^{100}$ 'FRTFPGIPKW' ${ }^{109}$ and activated MMP-3 but did not recognize the elongated peptide ${ }^{99}$ 'HFRTFPGIPKW ${ }^{109}$ and pro-MMP-3 (Figure 1A,B). The results were confirmed by western blot of in vitro activated MMP-3. Bands were detected at $45 \mathrm{kD}$ and $28 \mathrm{kD}$, but not at $52 \mathrm{kD}$, which is the size of the pro-MMP-3. All three bands were detected by the antibody recognizing the total MMP-3 antibody (Figure 1C). To ensure the specificity of the blot, primary antibody incubation was done including either the elongated peptide or the standard peptide. The signal was completely blocked only in the presence of the standard peptide.

\section{Table 1 Technical performance of act-MMP-3 assay}

\begin{tabular}{cc}
\hline Measurements & Technical characteristics \\
\hline Lower limit of detection & $33.7 \mathrm{pg} / \mathrm{mL}$ \\
Intra-assay variability & $3.1 \%$ \\
Inter-assay variability & $13.5 \%$ \\
Dilution recovery & Within $100 \pm 20 \%$ \\
Spiking recovery & Within $100 \pm 20 \%$ \\
\hline
\end{tabular}




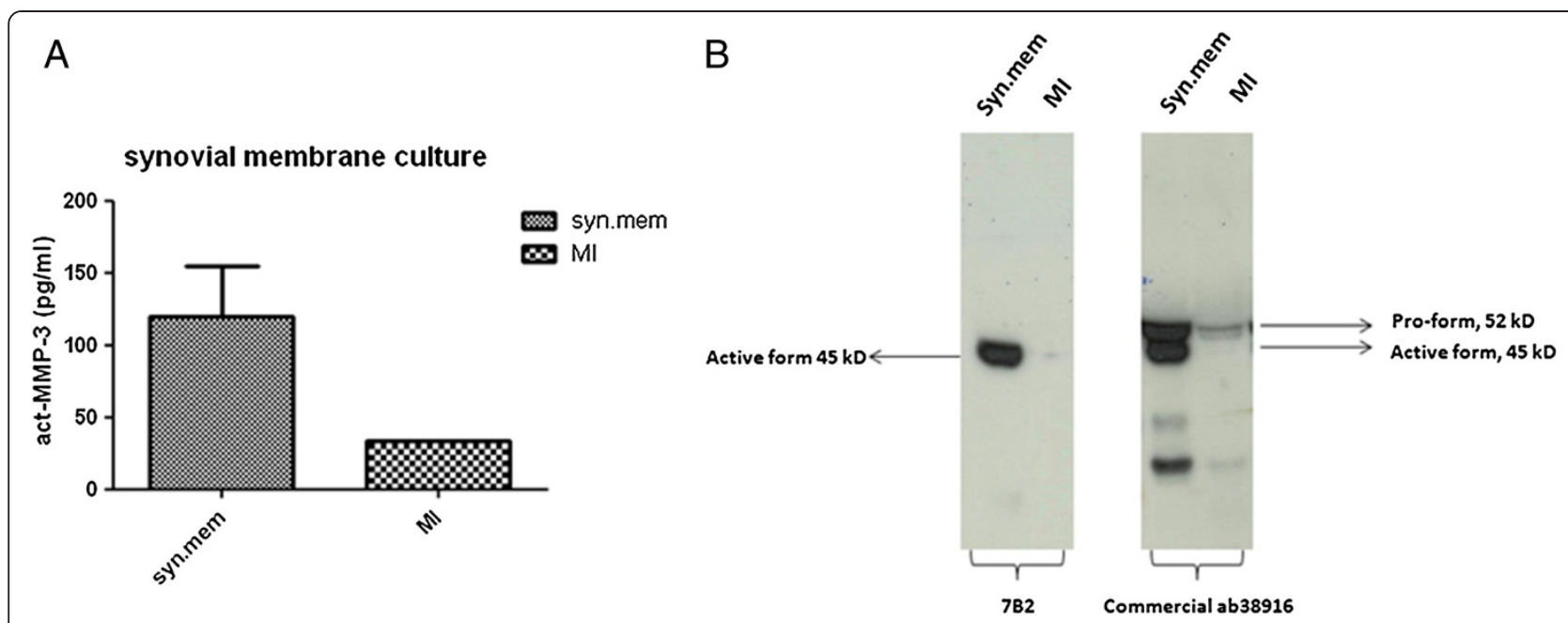

Figure 2 Act-MMP-3 profile in human synovial membrane culture. (A) Act-MMP-3 expression in synovial membrane culture supernatant. (B) Western blot results of synovial membrane culture.

Technical performance of the act-MMP-3 assay

The LLOD of the ELISA was $33.7 \mathrm{pg} / \mathrm{mL}$. The average intra- and inter-assay variations were $3.1 \%$ and $13.5 \%$, respectively. The dilution and spiking recovery of human serum were within $100 \pm 20 \%$ (Table 1 ). The data confirms technically robustness of the assay.

Assessment of antibody performance using material from human synovial membrane and cartilage ex vivo cultures We investigated the act-MMP-3 expression and release in human synovial membrane and HEX cultures, and as expected act-MMP-3 was expressed by human synovial membrane, compared to the negative control MI group (Figure 2A). The data was confirmed by western blotting, which again confirmed that the antibody only recognized the active form of MMP-3 (Figure 2B).

In HEX culture, stimulation with the pro-inflammatory cytokines TNF- $\alpha$ and oncostatin $M$ resulted in the release of act-MMP-3 into culture medium starting from the early culture stage (see Additional file 1: Figure S1), supporting the pathological relevance of act-MMP-3 in inflammatory joint diseases.

Act-MMP-3 levels in serum are related to inflammatory status in AS and RA

We investigated the association between baseline actMMP-3 levels and age, gender, disease duration in AS patients. The data showed that age and disease duration were not correlated to act-MMP-3 levels $(R=-0.046$ and $\mathrm{R}=-0.032$, respectively). Act-MMP-3 levels in male and female patients were not significantly different. We also assessed the correlation between baseline act-MMP-3 levels, baseline mSASSS, baseline BASDAI, baseline CRP and baseline ESR in AS patients (Table 2). Act-MMP-3 levels were not correlated with the disease burden markers, mSASSS and BASDAI ( $R=0.10$ and $R=0.06$, respectively), but were significantly correlated to CRP and ESR ( $R=0.42$ and $\mathrm{R}=0.38$, respectively, $\mathrm{P}<0.001$ ), which are markers of inflammation. Similar data were obtained in samples from RA patients, with baseline serum act-MMP-3 levels significantly correlated to CRP, but with no correlation with disease activity score (DAS) and health assessment questionnaire score (HAQ) (see Additional file 1: Table S1).

\section{Baseline act-MMP-3 levels predict anti-inflammatory} response to anti-TNF- $a$ treatment

To evaluate if baseline act-MMP-3 level had any predictive value response to anti-TNF- $\alpha$ treatment, correlations between baseline act-MMP-3 level, BASDAI reduction (change $<0$ ), CRP reduction (change $<0$ ) and ESR reduction (change $<0$ ) in AS patients were analyzed (Table 3 ). The data showed that baseline act-MMP-3 levels were significantly and positively correlated to the reduction in CRP and $\operatorname{ESR}(\mathrm{R}=0.44$ and $\mathrm{R}=0.39$, respectively, $\mathrm{P}<0.001$ ). There were no significant correlations between baseline

Table 2 Univariate correlation between clinical parameters and serum act-MMP-3 level in AS patients

\begin{tabular}{cccc}
\hline & \multicolumn{3}{c}{ Baseline active MMP3 (pg/ml) } \\
\cline { 2 - 4 } & $\mathbf{R}$ & $\mathbf{P}$ & $\mathbf{~ N}$ \\
\hline Age (years) & -0.05 & 0.55 & 173 \\
Disease duration (years) & -0.03 & 0.68 & 168 \\
CRP (mg/dl) & 0.42 & $<0.0001$ & 167 \\
ESR (mm/hour) & 0.38 & $<0.0001$ & 171 \\
Baseline BASDAl & 0.06 & 0.46 & 171 \\
Baseline mSASSS & 0.10 & 0.25 & 130 \\
\hline
\end{tabular}


Table 3 Univariate correlation between clinical characteristics change after treatment and serum act-MMP-3 level in AS patients

\begin{tabular}{cccc}
\hline & \multicolumn{3}{c}{ Baseline active MMP-3 $(\mathbf{p g} / \mathbf{m l})$} \\
\cline { 2 - 4 } & $\mathbf{R}$ & $\mathbf{P}$ & $\mathbf{N}$ \\
\hline CRP & 0.44 & $<0.0001$ & 107 \\
$\begin{array}{c}\text { Reduction }(\mathrm{mg} / \mathrm{dl}) \\
\text { ESR }\end{array}$ & 0.39 & $<0.0001$ & 113 \\
$\begin{array}{c}\text { Reduction (mm/hour) } \\
\text { BASDAl reduction }\end{array}$ & 0.10 & 0.26 & 120 \\
\hline
\end{tabular}

act-MMP-3 level and BASDAI reduction $(\mathrm{R}=0.10)$. Comparable results were observed for the RA patients. Baseline act-MMP-3 level did not predict DAS and HAQ change, but were correlated to CRP and ESR changes (see Additional file 1: Table S2).

To investigate if act-MMP-3 level can predict 2-year radiographic progression, correlation between baseline act-MMP-3 level and 2-year mSASSS increase (change $>0$ ) were analyzed. There was no significant correlation between baseline act-MMP-3 level and 2-year mSASSS change $(R=0.07)$.

\section{Serum levels of act-MMP-3 are reduced by anti-TNF- $a$ treatment}

To investigate if act-MMP-3 levels responded to antiTNF- $\alpha$ treatment, we measured serum levels of act-MMP3 in AS and RA patients at baseline and after anti-TNF- $\alpha$ treatment. A significant decrease in serum act-MMP-3 after treatment (Figure 3) was observed for both AS and RA, which showed the anti-TNF- $\alpha$ treatment, could effectively reduce act-MMP-3 levels, which correlates well with the previous findings that act-MMP-3 reflects the inflammatory status of the patients.

\section{Discussion}

MMP-3 is considered an important protease in joint damage where it has been shown to cleave a series of ECM proteins $[7,8]$. Monitoring act-MMP-3 levels is limited by the present commercial assays, which cannot distinguish the pro-form and act-form MMP-3. This illustrates a need for an assay that specifically measures act-MMP-3, and which can be used in ex vivo models and in clinical samples.

In this study, we successfully produced a monoclonal antibody specifically recognizing act-MMP-3, while no cross-reactivity to an elongated peptide with one more amino acid at the $\mathrm{N}$-terminal. Additionally, the antibody only detected act-MMP-3 and not pro-MMP-3, clearly confirming the specificity of the antibody. Furthermore, the antibody recognized both forms of act-MMP-3, namely the $45 \mathrm{kD}$ and $28 \mathrm{kD}$ forms, as expected since the low $\mathrm{Mw}$ form is generated by a C-terminal truncation $[14,27]$.

We applied two ex vivo models to clarify the pathological relevance of MMP-3 expression. As expected from literature $[28,29]$, we found high levels of act-MMP-3 in both synovial membrane culture and in Oncostatin $M$ and TNF- $\alpha$ stimulated human cartilage explants, when compared to controls.

In RA and AS patients, we successfully measured actMMP-3, and we found the concentration significantly decreased after anti-TNF- $\alpha$ treatment, which could indicate that act-MMP-3 could be used as a predictor of the treatment efficiency at the level of anti-inflammatory effects, whereas the levels did not correlate to or predict changes in disease activity scores. Furthermore, act-MMP-3 significantly correlated with CRP and ESR levels, which showed act-MMP-3 is a marker of inflammation. In previous studies, CRP, ESR correlated to mSASSS or BASDAI in AS patients $[4,19]$ and CRP weakly correlated to 2-years' mSASSS change [19], which indicate act-MMP-3 behaves different than the classical inflammatory markers.
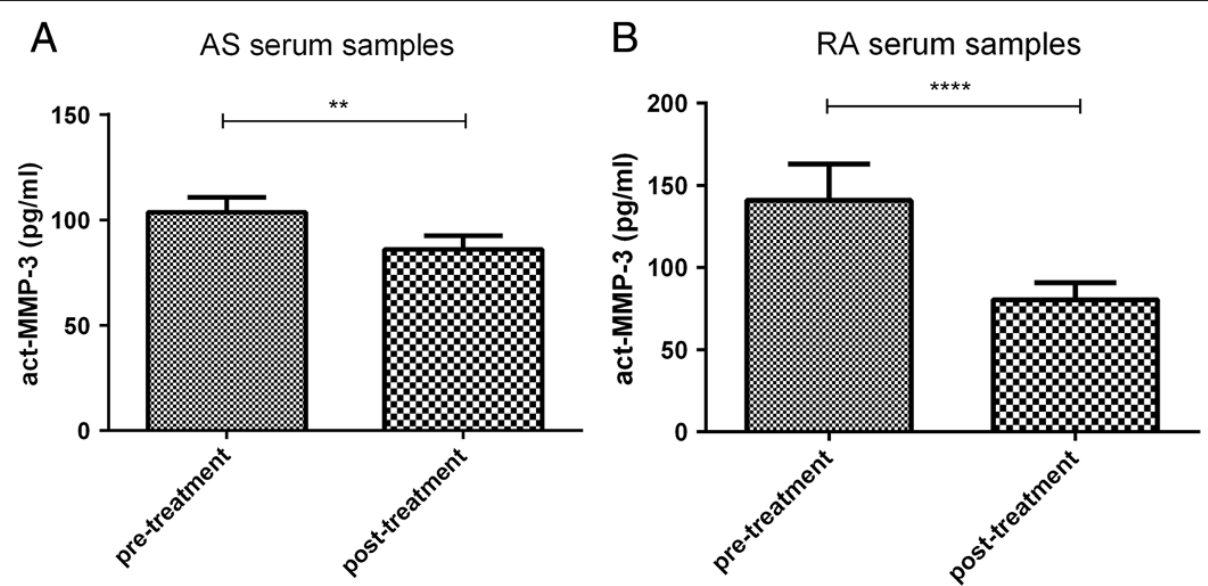

Figure 3 Act-MMP-3 assay measured in AS and RA patients at baseline and after treatment. The concentration of act-MMP-3 significant decreased after anti-TNF-a treatment in (A) AS patients $(n=98)$ and (B) RA patients $(n=41) .\left({ }^{* *}=P<0.01\right.$, $\left.{ }^{* * *}=P<0.0001\right)$. 
In a previous study, serum MMP-3 could predict 2-year mSASSS change [19]; however, we did not reproduce this data, which could be explained by two reasons. Firstly, the AS patients in the previous study did not receive antiTNF- $\alpha$ treatment. Secondly, an MMP-3 assay which measured both pro-MMP-3 and act-MMP-3 was used in the previous study, while in our study we only measured actMMP-3. We found act-MMP-3 only correlated with the inflammation markers CRP and ESR, but not to other measures of disease burden in AS (BASDAI, mSASSS) and RA (DAS, HAQ), and hence it appears that act-MMP-3 reflects other aspects of disease than total MMP-3.

However, there are some limitations to consider in relation to the detection of act-MMP-3 in human serum. Active forms of MMPs are known to bind to carrier proteins like TIMP and $\alpha-2$ macroglobulin $\left(\alpha_{2} \mathrm{M}\right)$ which are abundant in biological fluid [30,31]. $\alpha_{2} \mathrm{M}$ is a tetramers assembled by four $180 \mathrm{kD}$ subunits, which can capture actMMPs and shield them in the subunits [32], and this could skew the levels in serum towards lower levels. Furthermore, the interaction between $\alpha_{2} \mathrm{M}$ and act-MMP-3 is covalent and thereby virtually impossible to break without destroying antigen-antibody reaction. This could be the explanation for the low concentrations of free act-MMP-3 detected in human serum. Importantly, even at very low levels act-MMP-3 still has pathological relevance.

\section{Conclusions}

In summary, we have developed a highly sensitive and reproducible assay monitoring act-MMP-3 level in serum from humans. In ex vivo models, we confirmed act-MMP-3 can be expressed by synovial membrane and oncostatin $M$ and TNF- $\alpha$ stimulated human cartilage. Furthermore, we found act-MMP-3 in human serum showing correlation to inflammatory markers. Further studies are required to clarify, whether act-MMP-3 can serve as a predictive marker for outcome in chronic rheumatoid disorders.

\section{Additional file}

Additional file 1: Includes one figure and two tables. Figure $\mathrm{S} 1$ is act-MMP-3 measurement in the supernatant of HEX culture. Table S1 is the univariate correlation between clinical parameters and serum act-MMP3 level in RA patients. Table $\mathbf{S} 2$ is the univariate correlation between clinical characteristics change after treatment and serum act-MMP-3 level in RA patients.

\section{Abbreviations}

Act-MMP-3: Active matrix metalloproteinase-3; APMA: 4-aminophenylmercuric acetate; AS: Ankylosing spondylitis; BASDAl: Bath ankylosing spondylitis disease activity index; CRP: C-reactive protein; DAS: Disease activity score; ECM: Extracellular matrix; ESR: Erythrocyte sedimentation rate; HAQ: Health assessment questionnaire; HEX: Human cartilage explants culture; LLOD: Lower limit of detection; MI: Metabolic inactive; mSASSS: Modified stoke ankylosing spondylitis spinal score; QC: Quality control; RA: Rheumatoid arthritis; SEM: Standard error of the mean; $\mathrm{a}_{2} \mathrm{M}$ : $\mathrm{a}-2$ macroglobulin.

\section{Competing interests}

SS, ACBJ, MK, ASS, QLZ and KH are full time employees at Nordic Bioscience. Morten Karsdal holds stock in Nordic Bioscience. None of the authors received fees, bonuses or other benefits for the work described in the manuscript. Other authors have no competing interests.

\section{Authors' contributions}

SS did the study design, performed most of the experiments, data analysis and wrote the manuscript. $\mathrm{KH}, \mathrm{ACBJ}$ and MK assisted in study design and data analysis. ASS did the ex vivo human synovial membrane culture. WPM provided the clinical samples. TC provided the human synovial membrane samples. QLZ assisted in antibody development. All authors have read and approved the final manuscript.

\section{Acknowledgements}

We would like to thank the technicians Maibritt Andersen, Kathrine Marcher Mikkelsen of Nordic Bioscience for performing the human cartilage explant culture.

The biomarker portion of the study was supported by the Danish Research Foundation. Shu Sun receive funding from the Danish Agency for Science Technology and Innovation. Dr. Maksymowych is recipient of a Medical Scientist Award from Alberta Innovates-Health Solutions.

\section{Author details}

${ }^{1}$ Nordic Bioscience Biomarkers and Research, Herlev, Denmark. ${ }^{2}$ Nordic Bioscience Biomarkers and Research, Beijing, China. ${ }^{3}$ University of Alberta, Edmonton, Canada. ${ }^{4}$ Alberta Innovates-Health Solutions, Alberta, Canada.

${ }^{5}$ Orthopaedic Surgical Unit, Gentofte University Hospital, Hellerup, Denmark.

Received: 25 October 2013 Accepted: 13 March 2014

Published: 19 March 2014

\section{References}

1. Braun J, Sieper J: Ankylosing spondylitis. Lancet 2007, 369:1379-1390.

2. Bay-Jensen AC, Leeming DJ, Kleyer A, Veidal SS, Schett G, Karsdal MA: Ankylosing spondylitis is characterized by an increased turnover of several different metalloproteinase-derived collagen species: a crosssectional study. Rheumatol Int 2012, 32:3565-3572.

3. Chen $\mathrm{CH}$, Lin KC, Yu DT, Yang C, Huang F, Chen HA, Liang TH, Liao HT, Tsai CY, Wei JC, Chou CT: Serum matrix metalloproteinases and tissue inhibitors of metalloproteinases in ankylosing spondylitis: MMP-3 is a reproducibly sensitive and specific biomarker of disease activity. Rheumatology (Oxford) 2006, 45:414-420.

4. Yang C, Gu J, Rihl M, Baeten D, Huang F, Zhao M, Zhang H, Maksymowych WP, De KF, Veys EM, Yu DT: Serum levels of matrix metalloproteinase 3 and macrophage colony-stimulating factor 1 correlate with disease activity in ankylosing spondylitis. Arthritis Rheum 2004, 51:691-699.

5. Huber LC, Distler O, Tarner I, Gay RE, Gay S, Pap T: Synovial fibroblasts: key players in rheumatoid arthritis. Rheumatology (Oxford) 2006, 45:669-675.

6. Pap T, Muller-Ladner U, Gay RE, Gay S: Fibroblast biology. Role of synovial fibroblasts in the pathogenesis of rheumatoid arthritis. Arthritis Res 2000, 2:361-367.

7. Wu JJ, Lark MW, Chun LE, Eyre DR: Sites of stromelysin cleavage in collagen types II, IX, X, and XI of cartilage. J Biol Chem 1991, 266:5625-5628.

8. Flannery CR, Lark MW, Sandy JD: Identification of a stromelysin cleavage site within the interglobular domain of human aggrecan. Evidence for proteolysis at this site in vivo in human articular cartilage. J Biol Chem 1992, 267:1008-1014.

9. Knauper V, Wilhelm SM, Seperack PK, DeClerck YA, Langley KE, Osthues A, Tschesche H: Direct activation of human neutrophil procollagenase by recombinant stromelysin. Biochem J 1993, 295(Pt 2):581-586.

10. Shapiro SD, Fliszar CJ, Broekelmann TJ, Mecham RP, Senior RM, Welgus HG: Activation of the $92-k D a$ gelatinase by stromelysin and 4-aminophenylmercuric acetate. Differential processing and stabilization of the carboxyl-terminal domain by tissue inhibitor of metalloproteinases (TIMP). J Biol Chem 1995, 270:6351-6356.

11. Suzuki K, Enghild JJ, Morodomi T, Salvesen G, Nagase H: Mechanisms of activation of tissue procollagenase by matrix metalloproteinase 3 (stromelysin). Biochemistry 1990, 29:10261-10270.

12. Knauper V, Lopez-Otin C, Smith B, Knight G, Murphy G: Biochemical characterization of human collagenase-3. J Biol Chem 1996, 271:1544-1550. 
13. Visse R, Nagase H: Matrix metalloproteinases and tissue inhibitors of metalloproteinases: structure, function, and biochemistry. Circ Res 2003, 92:827-839.

14. Nagase H, Enghild JJ, Suzuki K, Salvesen G: Stepwise activation mechanisms of the precursor of matrix metalloproteinase 3 (stromelysin) by proteinases and (4-aminophenyl)mercuric acetate. Biochemistry 1990, 29:5783-5789.

15. Okada Y, Harris ED Jr, Nagase H: The precursor of a metalloendopeptidase from human rheumatoid synovial fibroblasts. Purification and mechanisms of activation by endopeptidases and 4-aminophenylmercuric acetate. Biochem J 1988, 254:731-741.

16. Kobayashi A, Naito S, Enomoto H, Shiomoi T, Kimura T, Obata K, Inoue K, Okada Y: Serum levels of matrix metalloproteinase 3 (stromelysin 1) for monitoring synovitis in rheumatoid arthritis. Arch Pathol Lab Med 2007, 131:563-570.

17. Posthumus MD, Limburg PC, Westra J, Cats HA, Stewart RE, van Leeuwen MA, van Rijswijk MH: Serum levels of matrix metalloproteinase-3 in relation to the development of radiological damage in patients with early rheumatoid arthritis. Rheumatology (Oxford) 1999, 38:1081-1087.

18. Houseman M, Potter C, Marshall N, Lakey R, Cawston T, Griffiths I, Young-Min S, Isaacs JD: Baseline serum MMP-3 levels in patients with Rheumatoid Arthritis are still independently predictive of radiographic progression in a longitudinal observational cohort at 8 years follow up. Arthritis Res Ther 2012, 14:R30.

19. Maksymowych WP, Landewe $\mathrm{R}$, Conner-Spady B, Dougados M, Mielants $H_{\text {, }}$ van der TH, Poole AR, Wang N, van der HD: Serum matrix metalloproteinase 3 is an independent predictor of structural damage progression in patients with ankylosing spondylitis. Arthritis Rheum 2007, 56:1846-1853.

20. Lohmander LS, Hoerrner LA, Lark MW: Metalloproteinases, tissue inhibitor, and proteoglycan fragments in knee synovial fluid in human osteoarthritis. Arthritis Rheum 1993, 36:181-189.

21. Hulejova H, Baresova V, Klezl Z, Polanska M, Adam M, Senolt L: Increased level of cytokines and matrix metalloproteinases in osteoarthritic subchondral bone. Cytokine 2007, 38:151-156.

22. Obata K, Iwata K, Okada Y, Kohrin Y, Ohuchi E, Yoshida S, Shinmei M, Hayakawa T: A one-step sandwich enzyme immunoassay for human matrix metalloproteinase 3 (stromelysin-1) using monoclonal antibodies. Clin Chim Acta 1992, 211:59-72

23. Barascuk N, Veidal SS, Larsen L, Larsen DV, Larsen MR, Wang J, Zheng Q, Xing R, Cao Y, Rasmussen LM, Karsdal MA: A novel assay for extracellular matrix remodeling associated with liver fibrosis: An enzyme-linked immunosorbent assay (ELISA) for a MMP-9 proteolytically revealed neo-epitope of type III collagen. Clin Biochem 2010, 43:899-904.

24. Gefter ML, Margulies DH, Scharff MD: A simple method for polyethylene glycol-promoted hybridization of mouse myeloma cells. Somatic Cell Genet 1977, 3:231-236

25. Bay-Jensen AC, Liu Q, Byrjalsen I, Li Y, Wang J, Pedersen C, Leeming DJ, Dam EB, Zheng Q, Qvist P, Karsdal MA: Enzyme-linked immunosorbent assay (ELISAs) for metalloproteinase derived type II collagen neoepitope, CIIM-increased serum CIIM in subjects with severe radiographic osteoarthritis. Clin Biochem 2011, 44:423-429.

26. Bay-Jensen AC, Karsdal MA, Vassiliadis E, Wichuk S, Marcher-Mikkelsen K, Lories R, Christiansen C, Maksymowych WP: Circulating citrullinated vimentin fragments reflect disease burden in ankylosing spondylitis and have prognostic capacity for radiographic progression. Arthritis Rheum 2013, 65:972-980.

27. Okada $Y$, Nagase $H$, Harris ED Jr: A metalloproteinase from human rheumatoid synovial fibroblasts that digests connective tissue matrix components. Purification and characterization. J Biol Chem 1986, 261:14245-14255.

28. Hui W, Rowan AD, Richards CD, Cawston TE: Oncostatin M in combination with tumor necrosis factor alpha induces cartilage damage and matrix metalloproteinase expression in vitro and in vivo. Arthritis Rheum 2003, 48:3404-3418

29. Okada Y, Takeuchi N, Tomita K, Nakanishi I, Nagase H: Immunolocalization of matrix metalloproteinase 3 (stromelysin) in rheumatoid synovioblasts (B cells): correlation with rheumatoid arthritis. Ann Rheum Dis 1989, 48:645-653.

30. Baker AH, Edwards DR, Murphy G: Metalloproteinase inhibitors: biological actions and therapeutic opportunities. J Cell Sci 2002, 115:3719-3727.
31. Cawston TE, Mercer E: Preferential binding of collagenase to alpha 2-macroglobulin in the presence of the tissue inhibitor of metalloproteinases. FEBS Lett 1986, 209:9-12.

32. Sottrup-Jensen L: Alpha-macroglobulins: structure, shape, and mechanism of proteinase complex formation. J Biol Chem 1989, 264:11539-11542.

doi:10.1186/1471-2474-15-93

Cite this article as: Sun et al.: The active form of MMP-3 is a marker of synovial inflammation and cartilage turnover in inflammatory joint diseases. BMC Musculoskeletal Disorders 2014 15:93.

\section{Submit your next manuscript to BioMed Central and take full advantage of:}

- Convenient online submission

- Thorough peer review

- No space constraints or color figure charges

- Immediate publication on acceptance

- Inclusion in PubMed, CAS, Scopus and Google Scholar

- Research which is freely available for redistribution

Submit your manuscript at www.biomedcentral.com/submit
C BioMed Central 